\title{
Pseudoprolapse of the anterior leaflet in chronic ischemic mitral regurgitation: Identification and repair
}

\author{
Sabet W. Hashim, MD, Samuel J. Youssef, MD, Bassem Ayyash, MD, Anthony J. Rousou, MD, \\ Sigurdur Ragnarsson, MD, Susan Collazo, BSN, and Arnar Geirsson, MD
}

\begin{abstract}
Objective: Recurrence rates as high as 30\% have been observed 6 months after treatment of chronic ischemic mitral regurgitation (CIMR) with isolated annuloplasty. We postulated that the high early recurrence rates resulted from the presence of untreated pseudoprolapse of the anterior leaflet.
\end{abstract}

\begin{abstract}
Methods: We conducted a retrospective study of all mitral valve repairs for CIMR performed by a single surgeon (S.W.H.) from 1995 to 2011. After annuloplasty, Gore-Tex neochordae were added if the high-pressure saline test indicated the presence of pseudoprolapse of the anterior leaflet.
\end{abstract}

\begin{abstract}
Results: A total of 47 patients underwent mitral valve repair for CIMR. Of the 47 patients, 24 (51\%) were found to have pseudoprolapse requiring the addition of neochordae. For all patients, the average age was 65.1 years, and $65.2 \%$ were men. Fourteen $(30 \%)$ had had a preoperative intra-aortic balloon pump placed by cardiologists. Fourteen $(30 \%)$ had severe pulmonary hypertension. Concomitant coronary artery bypass grafting was performed in 40 patients, with an average of 2.2 grafts; 7 had previously undergone coronary artery bypass grafting. Mitral Carpentier-Edwards physio annuloplasty rings were used in all patients with a mean size of $29 \mathrm{~mm}$. One patient died postoperatively. Follow-up data were available for all 47 patients at an average of 4.9 years. The 5 -year survival rate was $82.5 \%$. The mean pre- and postoperative New York Heart Association class, ejection fraction, and mitral regurgitation grade were 3 and $1.52(P<.0001), 34 \%$ and $41 \%(P=.0006)$, and 3.51 and $1.08(P<.0001)$, respectively. Two patients developed greater than moderate mitral regurgitation.
\end{abstract}

Conclusions: Effective repair of CIMR should include surgical techniques to correct pseudoprolapse of the anterior leaflet, when present. The selective addition of Gore-Tex neochordae to an undersized annuloplasty nearly eliminates recurrent regurgitation after mitral valve repair for CIMR. (J Thorac Cardiovasc Surg 2012;143:S33-7)

The prognosis of patients with ischemic heart disease is negatively affected by the presence of mitral regurgitation (MR). An increasing severity of regurgitation is associated with a progressively worse 5-year survival. ${ }^{1}$ The current recommendations for the treatment of moderate to severe chronic ischemic mitral regurgitation (CIMR) support the repair or replacement of the mitral valve in addition to coronary revascularization. ${ }^{2-4}$ Reduction mitral annuloplasty using a flexible ring ( 1 size smaller than measured) has been associated with recurrence rates of up to $30 \%$ within 6 months. ${ }^{5,6}$

Having frequently observed an eccentric posteriorly directed jet on the intraoperative transesophageal

\footnotetext{
From the Section of Cardiac Surgery, Yale University School of Medicine, New Haven, Conn.

Disclosures: Sabet W. Hashim, Samuel J. Youssef, Bassem Ayyash, Anthony J. Rousou, Sigurdur Ragnarsson, Susan Collazo, and Arnar Geirsson have nothing to disclose with regard to commercial support.

Presented at The American Association for Thoracic Surgery Mitral Conclave, New York, New York, May 5-6, 2011.

Received for publication May 15, 2011; revisions received Sept 15, 2011; accepted for publication Sept 28, 2011; available ahead of print Nov 4, 2011.

Address for reprints: Sabet W. Hashim, MD, Section of Cardiac Surgery, Yale University School of Medicine, 333 Cedar Street, Boardman 204, New Haven, CT 06520 (E-mail: sabet.hashim@yale.edu).

$0022-5223 / \$ 36.00$

Copyright (c) 2012 by The American Association for Thoracic Surgery doi:10.1016/j.jtcvs.2011.09.063
}

echocardiogram (TEE), we hypothesized that a functional prolapse of the anterior leaflet was a major cause of recurrence of regurgitation after a seemingly successful repair. This functional prolapse results from the anterior leaflet overriding the posterior leaflet, either below the annulus (Carpentier IIIB) or above the annulus (Carpentier II). ${ }^{7}$ The term "pseudoprolapse" was coined to describe the functional prolapse seen in ischemic MR with normal leaflets and to differentiate it from the classic prolapse of myxomatous MR associated with excess leaflet tissue.

The dominant strategy at our institution has been to identify pseudoprolapse, correct it with Gore-Tex neochordae, and use a single-undersized rigid annuloplasty ring. The present report analyzes the outcome of all patients at our institution who underwent mitral repair for CIMR by a single surgeon (S.W.H.) using isolated annuloplasty or annuloplasty with neochordae.

\section{MATERIALS AND METHODS}

The institutional review board of Yale University reviewed and approved the present study with a waiver of consent. From 1995 to 2011, 47 patients were identified who underwent surgical treatment for CIMR, including coronary artery bypass grafting and mitral valve repair. Postoperative echocardiographic studies were available for 42 patients, with a mean follow-up of 2.5 years. The degree of MR was classified as 0 , absent; 1 , mild; 2 , moderate; 3 , moderate-severe; and 4 , severe. 


\section{Abbreviations and Acronyms \\ CIMR = chronic ischemic mitral regurgitation \\ LVEDD $=$ left ventricular end-diastolic dimension \\ MR = mitral regurgitation \\ NYHA $=$ New York Heart Association \\ TEE $=$ transesophageal echocardiogram}

The perioperative demographics and risk factors were determined from the patient charts. Postoperative echocardiographic follow-up data were collected from hospital records and reports supplied by cardiologists or primary care physicians. No reinterpretation of the studies was performed to avoid the introduction of bias.

Follow-up data were available for all 47 patients, with a mean of 4.90 years (range 3.75 to 6.06 ). Mortality data were obtained by chart review, telephone calls to the patients' families, and from the United States Social Security Death Index.

A subgroup analysis was performed using the left ventricular enddiastolic dimension (LVEDD) of greater or less than $6 \mathrm{~cm}$.

\section{Surgical Technique}

Our repair strategy included the following: ring sutures were placed. One or 2 Gore-Tex neochordae were anchored to the papillary muscle. The anterior leaflet surface area was measured and a 1-downsized Carpentier-Edwards physio (Edwards, Irvine, Calif) annuloplasty ring was seated. The valve was tested with high-pressure saline injection into the left ventricle. If a leak was identified or if an asymmetric line of coaptation was present, the involved area was marked with ink. The chordae were then passed through the inked area. A simple edge-to-edge Prolene stitch was placed and the knot was used as a reference for tying down the Gore-Tex neochordae. The Prolene edge to edge stitch was then removed and the ring sutures were tied. The final steps were repeated until a perfect line of closure was obtained.

\section{Statistical Analysis}

Independent statistical analysis was performed using SAS, version 9.2 (SAS Institute, Cary, NC). The data are presented as the mean and $95 \%$ confidence intervals (CIs). The mean values were compared using paired $t$ tests. Signed rank tests were also performed on the ordinal variables, the NYHA class and MR grade. The $t$ tests were used to test the equality of mean differences in these measures between the LVEDD groups (LVEDD $<6 \mathrm{~cm}$ versus LVEDD $\geq 6 \mathrm{~cm}$ ). The survival rates were compared using the Kaplan-Meier estimates and the log-rank test. $P<.05$ was used as the threshold for statistical significance in all tests.

\section{RESULTS \\ Demographics}

From 1995 to 2011, 47 patients underwent mitral valve repair for CIMR. Of the 47 patients, $23(49 \%)$ underwent isolated undersized annuloplasty and $24(51 \%)$ underwent annuloplasty with neochordae. The average age was 66 years, and $64 \%$ were men. Fourteen patients $(30 \%)$ had an intra-aortic balloon pump placed by cardiologists before surgery, and 14 patients $(30 \%)$ had severe pulmonary hypertension (systolic blood pressure $>60 \mathrm{~mm} \mathrm{Hg}$ ).

Concomitant coronary artery bypass grafting was performed in 40 patients with an average of 2.2 grafts. The remaining 7 had undergone previous coronary artery bypass grafting. Mitral Carpentier-Edwards physio rings were used in all patients with a mean size of $29 \mathrm{~mm}$ and median size of $28 \mathrm{~mm}$. The average crossclamp and cardiopulmonary bypass time was 91 and 125 minutes, respectively.

Of the 47 patients, $24(51 \%)$ were found to have pseudoprolapse of the anterior leaflet requiring neochordae in addition to annuloplasty. The locations of the neochordae were A2 $(\mathrm{n}=2), \mathrm{A} 3(\mathrm{n}=12)$, and A2 plus A3 $(\mathrm{n}=10)$.

\section{Outcomes}

One patient died on postoperative day 28 secondary to pulmonary failure. One patient experienced a stroke and one developed a sternal wound infection.

The mean pre- and postoperative values are listed in Table 1. Significant difference were found in the values for NYHA, ejection fraction, and MR at 3 and $1.52(P<$ $.0001), 34 \%$ and $41 \%(P=.0006)$, and 3.51 and 1.08 $(P<.0001)$, respectively.

Echocardiographic follow-up demonstrated 2 recurrences with greater than $2+\mathrm{MR}$. Both occurred within 1 year after surgery, 1 in each subgroup. No late recurrences developed. The freedom from recurrence rate during the follow-up period was $92.7 \%$ (95\% CI $82.9 \%$ to $100 \%$; Figure $1, B$ ).

The primary endpoint was all-cause mortality. Twelve patients died during the follow-up period. Two patients underwent cardiac transplantation, both without MR. The overall 5-year survival rate was $82.5 \%$ (95\% CI $69.3 \%$ to $95.7 \%$ ) at 4.9 years (Figure 1,C). The median survival time for the overall population was 10.74 years.

\section{Subgroup Analysis}

Nineteen patients with a LVEDD of $6 \mathrm{~cm}$ or greater had significant preoperative to postoperative improvement in the LVEDD from 6.63 to $6.23 \mathrm{~cm}(P=.04)$, left ventricular ejection fraction from $26 \%$ to $35 \%(P=.0103)$, NYHA class from 3.06 to $1.61(P<.001)$, and MR grade from 3.68 to $1.16(P<.001)$. A trend for a decrease in the left ventricular end-systolic dimension was seen (from 5.74 preoperatively to $5.05 \mathrm{~cm}$ postoperatively, $P=.0850$ ) without reaching statistical significance.

Twenty-eight patients with a LVEDD of less than $6 \mathrm{~cm}$ had significant preoperative to postoperative improvement in the left ventricular ejection fraction from $39 \%$ to $46 \%$ $(P=.0269)$, NYHA class from 2.95 to $1.45(P<.001)$, and MR grade from 3.39 to $1.0(P \leq .001)$. No difference was seen in LVEDD (5.07 vs $5.26 \mathrm{~cm}, P=.690$ ) or left ventricular end-systolic dimension (3.64 vs. $3.86 \mathrm{~cm}$, $P=.457)$.

Mid-term follow-up data were available for all patients in the subgroup analysis. The 5-year survival rate in the 6-cm or greater LVEDD group was $70.5 \%$ (95\% CI $45 \%$ to 
TABLE 1. Comparison between pre- and postoperative values for overall group

\begin{tabular}{lcclccrr}
\hline & \multicolumn{2}{c}{ Preoperative } & & \multicolumn{2}{c}{ Postoperative } & \\
\cline { 2 - 3 } \multicolumn{1}{c}{ Variable } & Mean & $\mathbf{9 5} \% \mathbf{C I}$ & & Mean & $\mathbf{9 5} \% \mathbf{C I}$ & P value \\
\hline EF $(\%)$ & 34 & $0.30-0.38$ & & 41 & $0.36-0.45$ & .0006 \\
LVEDD & 5.80 & $5.48-6.12$ & & 5.68 & $5.38-5.97$ & .2449 \\
LVESD & 4.58 & $4.16-4.99$ & & 4.36 & $3.97-4.74$ & .1944 \\
LA Diameter & 4.67 & $4.37-4.97$ & & 4.75 & $4.35-5.15$ & .2722 \\
MR Grade & 3.51 & $3.35-3.67$ & & 1.08 & $0.74-1.41$ & $<.0001$ \\
NYHA Class & 3.00 & $2.76-3.24$ & & 1.52 & $1.25-1.78$ & $<.0001$ \\
\hline
\end{tabular}

$C I$, confidence interval; $E F$, ejection fraction; $L A$, left atrial; $L V E D D$, left ventricular end-diastolic dimension; $L V E S D$, left ventricular end-systolic dimension; $M R$, mitral regurgitation; NYHA, New York Heart Association.

$95.9 \%)$ and was $91 \%(95 \%$ CI $79 \%$ to $100 \%)$ in the less than 6-cm LVEDD group.

Using the log-rank test, a trend was found for improved survival for the less than 6-cm group compared with the 6-cm or greater group (log-rank $P=.64)$ without reaching statistical significance (Figure 1,D).

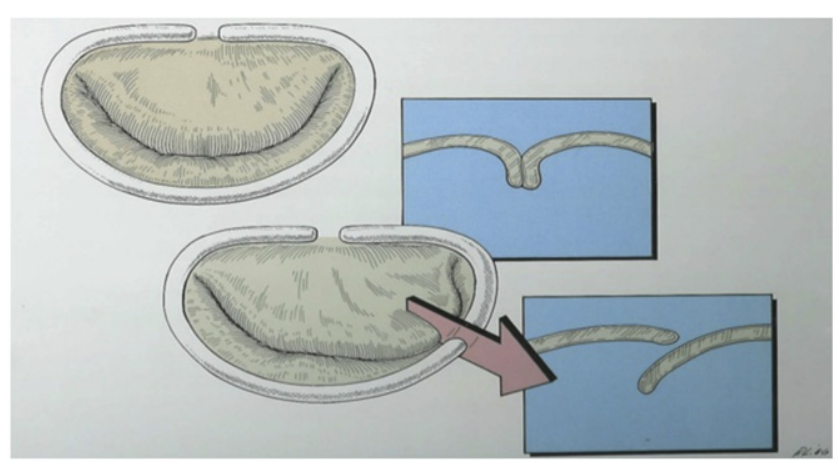

A

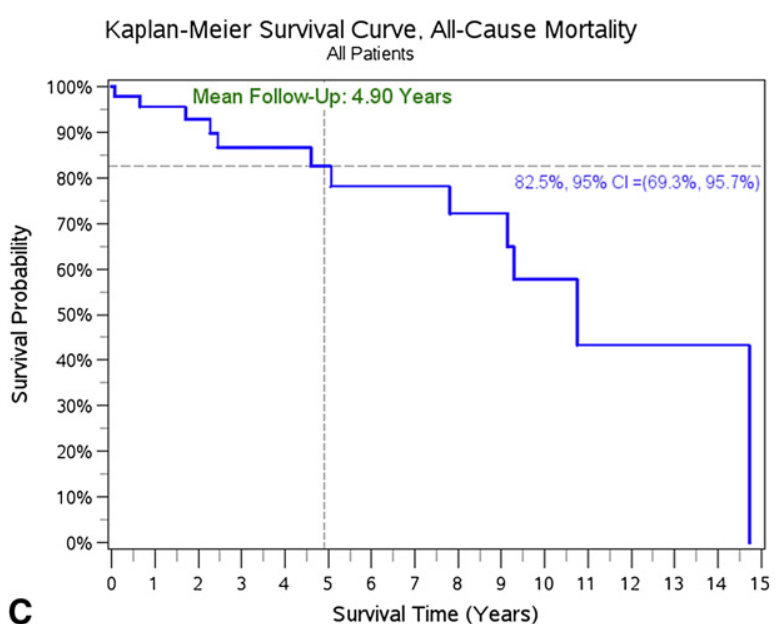

\section{DISCUSSION}

Ischemic remodeling results in subtle, yet complex, geometric changes of the ventricle and papillary muscles that negatively affect ventricular function and mitral valve competence. ${ }^{8,9}$ Clues regarding the pattern of regurgitation were taken from the echocardiographic studies. ${ }^{10,11}$ In CIMR, the transthoracic echocardiogram typically shows a central regurgitant jet. However, on intraoperative TEE, an eccentric jet was commonly detected, either isolated or combined with a central jet. This eccentric jet was always posteriorly directed, revealing the presence of functional anterior prolapse.

The treatment of CIMR has relied on an undersized annuloplasty using a small-size ring to reduce the anteroposterior diameter of the annulus and increase the coaptation surface. A high early recurrence rate of up to $30 \%$ has been observed using this technique. ${ }^{5,6}$ It is safe to assume that in those series, the intraoperative saline test results were satisfactory, and the patients had no intraoperative
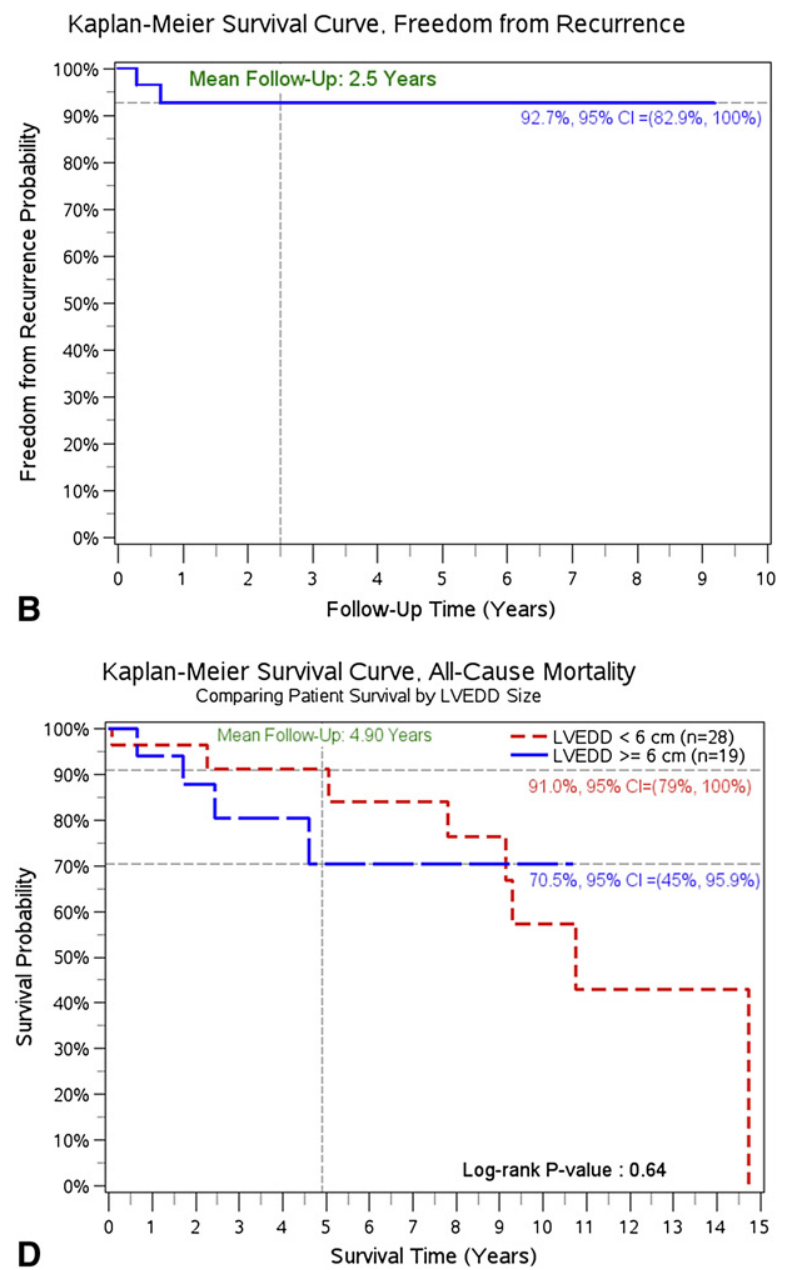

FIGURE 1. A, Top, Ideal coaptation of anterior and posterior mitral valve leaflets. A, Bottom, Pseudoprolapse of anterior leaflet as demonstrated by overriding of the posterior leaflet by the anterior leaflet. B, Overall freedom from recurrence. C, Five-year overall survival. D, Subgroup survival analysis according to left ventricular end-diastolic dimension $(L V E D D)$ greater than 6 or less than $6 \mathrm{~cm}$. 
MR. The discovery of MR in the first few months after surgery might have been the consequence of an insufficient surface of coaptation in the face of the increased loading conditions associated with patients resuming their normal activity.

Braun and colleagues, ${ }^{12}$ aware of the limitation of the undersized annuloplasty technique, proposed the use of restrictive annuloplasty that downsized the ring by 2 sizes instead of 1 . Although restrictive annuloplasty might add 1 or $2 \mathrm{~mm}$ to the surface of coaptation, it has been shown to produce mitral stenosis, ${ }^{13,14}$ with gradients up to 8 $\mathrm{mm} \mathrm{Hg}$ or more at rest. ${ }^{15}$ In 1 series, $80 \%$ of the recurrences after restricted annuloplasty were associated with restricted posterior leaflet motion. ${ }^{15}$ This finding would suggest that the recurrences could have been prevented if the alignment of the leaflets had been restored in the original operation.

Carpentier, McCarthy, and Adams, recognizing the asymmetric coaptation at the level of $\mathrm{P} 3$, designed the IMR ETlogix (Edwards, Irvine CA) ring, which added additional narrowing of the anteroposterior diameter in the area corresponding to P2-P3. ${ }^{16}$ The goal of this measure was to increase the coapting surface of the leaflets at their points of asymmetry without resorting to the use of a restrictive ring. However, the shape of the IMR ring predetermined the location of the asymmetry in the leaflets and did not always correlate with the anatomy of a particular patient. ${ }^{17}$

Kron and colleagues ${ }^{18}$ advocated relocating the posterior papillary muscle closer to the annulus. This technique has proved efficacious in treating MR associated with inferior wall myocardial infarction, but it does not address MR secondary to anterior wall myocardial infarction. Others have proposed adjunctive techniques such as secondary chord cutting, ${ }^{19}$ papillary muscle sling, ${ }^{20}$ and papillary muscle relocation and leaflet augmentation. ${ }^{21,22}$ Each of these techniques addresses a particular anatomic setting. ${ }^{23}$ The current inconsistent and incomplete success of repair techniques has led the National Heart, Lung, and Blood Institute to initiate a prospective trial of mitral repair versus replacement for the treatment of ischemic MR. ${ }^{24}$

In our approach to CIMR, we have applied the same principle of leaflet alignment that has been used in the treatment of myxomatous MR. Our strategy was based on the recognition that in a subgroup of ischemic patients, there is a pseudoprolapse of the anterior leaflet. This pseudoprolapse, if uncorrected, would lead to a recurrence of MR. ${ }^{25}$ Without addressing the pseudoprolapse, an isolated annuloplasty could only produce a partial apposition of the inverted portions of the leaflets. In contrast, treatment of the pseudoprolapse with a realignment of the planes of the opposing leaflets would allow the annuloplasty to achieve $100 \%$ of the possible coaptation. Correction of the anterior pseudoprolapse was achieved with Gore-Tex neochordae applied to $\mathrm{A} 3$ or $\mathrm{A} 2$, or both. All patients with CIMR, whether presenting with type II or IIIB regurgitation, were approached with the same strategy and surgical technique.

During the repair, we challenged the coaptation line with high-pressure saline injection to detect any protrusion of the anterior leaflet at the level of A3 and/or A2, especially if an eccentric jet had been detected on the intraoperative TEE. Any asymmetric closure, even without a leak (Figure 1, A), was corrected with neochordae. The use of a temporary edge-to-edge suture facilitated an exact measurement of the length of Gore-Tex neochordae and precise leaflet alignment. This adjunct technique was an essential step because ischemic patients, unlike myxomatous patients, have no excess leaflet tissue to compensate for misalignment.

We were concerned that, in Carpentier type IIIB, the line of coaptation falling below the plane of the annulus would produce interscallop regurgitation and that the continued ventricular remodeling would lead to MR recurrence. The results of our study have alleviated both of these concerns.

Correcting the pseudoprolapse in ischemic MR achieved the near elimination of recurrence and improved midterm survival. In our series, no late recurrences developed, even though $34 \%$ of our patients exhibited postrepair ventricular enlargement. The only 2 instances of recurrence developed during the first year after surgery, suggesting technical failure of the repair rather than a remodeling etiology. Our 93\% 5-year freedom from recurrence rate strongly suggests that ventricular remodeling does not result in MR recurrence. The ventricular enlargement that has followed other repair techniques is most likely a consequence, rather than a cause, of the failed repairs. ${ }^{26}$ Our data have not confirmed the findings by others of reverse remodeling that occurs after the correction of MR. When we analyzed the 2 groups, the only statistically significant result was that of regression of LVEDD in the larger $(>6 \mathrm{~cm})$ ventricles.

Our results indicate that the preoperative TEE can be used to guide operative strategies. Some patients with ischemic MR have no pseudoprolapse, and the TEE will show a central jet that corresponds to symmetric dilation of the annulus. In those patients, a simple undersized annuloplasty should suffice. In contrast, in patients with CIMR and pseudoprolapse of the anterior leaflet, TEE will reveal an eccentric or dual jet. In this subgroup of patients, neochordae should be used in addition to annuloplasty. We recommend that a preoperative TEE be performed in all patients with CIMR. If the TEE shows an eccentric jet pattern, patients should be referred to surgeons who are practiced in anterior leaflet repair.

The authors would like to thank Maria Ciarleglio for her assistance in statistical analysis and review. 


\section{References}

1. Grigioni F, Detaint D, Avierinos JF, Scott C, Tajik J, Enriquez-Sarano M. Contribution of ischemic mitral regurgitation to congestive heart failure after myocardial infarction. J Am Coll Cardiol. 2005;45:260-7.

2. Cohn LH, Couper GS, Kinchla NM, Collins JJ Jr. Decreased operative risk of surgical treatment of mitral regurgitation with or without coronary artery disease. J Am Coll Cardiol. 1990;16:1575-8.

3. Grossi EA, Woo YJ, Patel N, Goldberg JD, Schwartz CF, Subramanian VA, et al. Outcomes of coronary artery bypass grafting and reduction annuloplasty for functional ischemic mitral regurgitation: a prospective multicenter study (randomized evaluation of a surgical treatment for off-pump repair of the mitral valve). J Thorac Cardiovasc Surg. 2011;141:91-7.

4. Fattouch K, Sampognaro R, Speziale G, Salardino M, Novo G, Caruso M, et al. Impact of moderate ischemic mitral regurgitation after isolated coronary artery bypass grafting. Ann Thorac Surg. 2010;90:1187-94.

5. Hung J, Papakostas L, Tahta SA, Hardy BG, Bollen BA, Duran CM, et al. Mechanism of recurrent ischemic mitral regurgitation after annuloplasty: continued LV remodeling as a moving target. Circulation. 2004;110(11 Suppl. 1):II85-90.

6. McGee EC, Gillinov AM, Blackstone EH, Rajeswaran J, Cohen G, Najam F, et al. Recurrent mitral regurgitation after annuloplasty for functional ischemic mitral regurgitation. J Thorac Cardiovasc Surg. 2004;128:916-24.

7. Carpentier A. Cardiac valve surgery-the "French correction." J Thorac Cardiovasc Surg. 1983;86:323-37.

8. Onorati F, Rubino AS, Marturano D, Pasceri E, Santarpino G, Zinzi S, et al. Midterm clinical and echocardiographic results and predictors of mitral regurgitation recurrence following restrictive annuloplasty for ischemic cardiomyopathy. J Thorac Cardiovasc Surg. 2009;138:654-62.

9. Cohn LH, Rizzo RJ, Adams DH, Couper GS, Sullivan TE, Collins JJ Jr, et al. The effect of pathophysiology on the surgical treatment of ischemic mitral regurgitation: operative and late risks of repair versus replacement. Eur J Cardiothorac Surg. 1995;9:568-74

10. Stewart WJ, Currie PJ, Salcedo EE, Klein AL, Marwick T, Agler DA, et al. Evaluation of mitral leaflet motion by echocardiography and jet direction by Doppler color flow mapping to determine the mechanisms of mitral regurgitation. J Am Coll Cardiol. 1992;20:1353-61.

11. Gallet B. [Use of echocardiography in mitral regurgitation for the assessment of its mechanism and etiology for the morphological analysis of the mitral valve]. Ann Cardiol Angeiol (Paris). 2003;52:70-7.

12. Braun J, van de Veire NR, Klautz RJ, Versteegh MI, Holman ER, Westenberg JJ, et al. Restrictive mitral annuloplasty cures ischemic mitral regurgitation and heart failure. Ann Thorac Surg. 2008;85:430-7.

13. Magne J, Senechal M, Mathieu P, Dumesnil JG, Dagenais F, Pibarot P. Restrictive annuloplasty for ischemic mitral regurgitation may induce functional mitral stenosis. J Am Coll Cardiol. 2008;51:1692-701.
14. Kubota K, Otsuji Y, Ueno T, Koriyama C, Levine RA, Sakata R, et al. Functional mitral stenosis after surgical annuloplasty for ischemic mitral regurgitation: importance of subvalvular tethering in the mechanism and dynamic deterioration during exertion. J Thorac Cardiovasc Surg. 2010;140:617-23.

15. Williams ML, Daneshmand MA, Jollis JG, Horton JR, Shaw LK, Swaminathan M, et al. Mitral gradients and frequency of recurrence of mitral regurgitation after ring annuloplasty for ischemic mitral regurgitation. Ann Thorac Surg. 2009;88:1197-201.

16. Bothe W, Swanson JC, Ingels NB, Miller DC. How much septal-lateral mitral annular reduction do you get with new ischemic/functional mitral regurgitation annuloplasty rings? J Thorac Cardiovasc Surg. 2010;140:117-21. 21e1-21e3.

17. Bothe W, Kvitting JP, Stephens EH, Swanson JC, Liang DH, Ingels NB Jr, et al Effects of different annuloplasty ring types on mitral leaflet tenting area during acute myocardial ischemia. J Thorac Cardiovasc Surg. 2011;141:345-53.

18. Kron IL, Green GR, Cope JT. Surgical relocation of the posterior papillary muscle in chronic ischemic mitral regurgitation. Ann Thorac Surg. 2002;74: 600-1.

19. Komeda M, Shimamoto T. Cutting secondary chordae and placing dual taut stitches between the anterior mitral fibrous annulus and the heads of each papillary muscle to treat ischemic mitral regurgitation without deteriorating left ventricular function. J Thorac Cardiovasc Surg. 2008;135:226-7.

20. Hvass U, Joudinaud T. The papillary muscle sling for ischemic mitral regurgitation. J Thorac Cardiovasc Surg. 2010;139:418-23.

21. Langer F, Rodriguez F, Cheng A, Ortiz S, Nguyen TC, Zasio MK, et al. Posterior mitral leaflet extension: an adjunctive repair option for ischemic mitral regurgitation? J Thorac Cardiovasc Surg. 2006;131:868-77.

22. Robb JD, Minakawa M, Koomalsingh KJ, Shuto T, Jassar AS, Ratcliffe SJ, et al Posterior leaflet augmentation improves leaflet tethering in repair of ischemic mitral regurgitation. Eur J Cardiothorac Surg. May 3, 2011 [Epub ahead of print].

23. Anyanwu AC, Adams DH. Why do mitral valve repairs fail? J Am Soc Echocardiogr. 2009;22:1265-8.

24. National Heart, Lung, and Blood Institute. Comparing the effectiveness of repairing versus replacing the heart's mitral valve in people with severe chronic ischemic mitral regurgitation. Available at: www.clinicaltrials.gov/ct2/show/ study/NCT00807040?term $=$ mitral+valve-repair\&rank=3. Accessed October $22,2011$.

25. Hashim SW, Rousou AJ, Geirsson A, Ragnarsson S. Solving the puzzle of chronic ischemic mitral regurgitation. Yale J Biol Med. 2008;81:167-73.

26. Onorati F, Santarpino G, Marturano D, Rubino AS, Pasceri E, Zinzi S, et al. Successful surgical treatment of chronic ischemic mitral regurgitation achieves lef ventricular reverse remodeling but does not affect right ventricular function. J Thorac Cardiovasc Surg. 2009;138:341-51. 